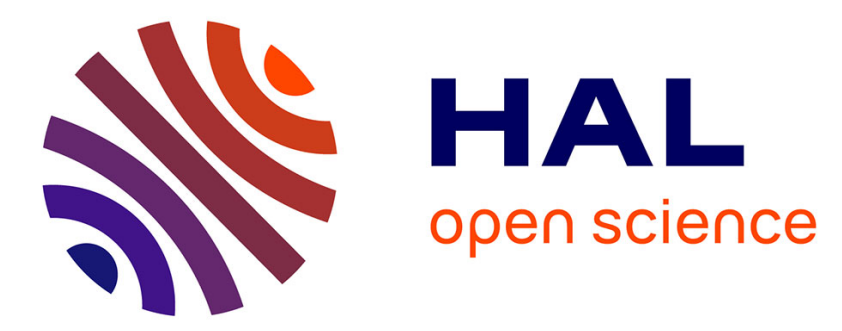

\title{
Low band-gap polymer brushes: Influence of the end-group on the morphology of core-shell nanoparticles
}

Adèle Gapin, Hisham Idriss, Sylvie Blanc, Laurent Billon, Marie-Hélène Delville, Antoine Bousquet, Christine Lartigau-Dagron

\section{To cite this version:}

Adèle Gapin, Hisham Idriss, Sylvie Blanc, Laurent Billon, Marie-Hélène Delville, et al.. Low band-gap polymer brushes: Influence of the end-group on the morphology of core-shell nanoparticles. Reactive and Functional Polymers, 2020, 155, 104700 (9 p.). 10.1016/j.reactfunctpolym.2020.104700 . hal02917302

\section{HAL Id: hal-02917302 \\ https://hal-univ-pau.archives-ouvertes.fr/hal-02917302}

Submitted on 17 Sep 2020

HAL is a multi-disciplinary open access archive for the deposit and dissemination of scientific research documents, whether they are published or not. The documents may come from teaching and research institutions in France or abroad, or from public or private research centers.
L'archive ouverte pluridisciplinaire HAL, est destinée au dépôt et à la diffusion de documents scientifiques de niveau recherche, publiés ou non, émanant des établissements d'enseignement et de recherche français ou étrangers, des laboratoires publics ou privés. 


\title{
Low Band-Gap Polymer Brushes: Influence of the End- group on the Morphology of Core-Shell Nanoparticles
}

Adèle Gapin ${ }^{1}$, Hisham Idriss ${ }^{1}$, Sylvie Blanc ${ }^{1}$, Laurent Billon ${ }^{1}$, Marie-Hélène Delville ${ }^{2}$, Antoine Bousquet $^{1, *}$, Christine Lartigau-Dagron ${ }^{1, *}$

1. CNRS/Université de Pau et des Pays de 1'Adour/E2S UPPA, IPREM CNRS-UMR 5254 Hélioparc, 2 avenue Président Angot, 64053 Pau Cedex 9, France

2. CNRS, Université de Bordeaux, ICMCB, 87 avenue du Dr A. Schweitzer, Pessac F-33608, France

Corresponding author : Antoine Bousquet, antoine.bousquet@univ-pau.fr, +33540175104

\section{Keywords.}

low band-gap polymer $\bullet$ hybrid nanoparticles $\bullet$ grafting $\bullet$ Stille polycondensation $\bullet$ zinc oxide $\bullet$ silane •

\begin{abstract}
.
An efficient strategy is described to prepare electron donor/acceptor hybrid nanoparticles by anchoring a low band-gap polymer onto zinc oxide spheres. Functional macromolecules, bearing triethoxysilane or catechol terminal groups, were synthesized by polycondensation, using a ternary blend reaction, i.e. mixing two monomers and an end-capper. Importantly, and in agreement with Carothers theory, the amount of end-capper allowed to control the chains molar mass. $\mathrm{ZnO}$ spherical nanoparticles were then grafted with the polymer chains and TEM images confirmed that core@shell materials were formed. The surface morphology of these hybrid materials was anchoring agent dependent. When silane functionalized polymers were used, cross-linked aggregates were obtained due to competition between self-condensation of silanes and reaction with $\mathrm{ZnO}$ surface hydroxyl groups. On the contrary, well-dispersed core-shell particles were synthesized with catechol polymers as anchoring agents. This grafting onto methodology led to patchy nanoparticles on which both zinc oxide and polymer surfaces were accessible. The optical
\end{abstract}


properties of the hybrid material were ascertained by UV-visible absorption and photoluminescence to show a specific quenching of the polymer fluorescence by the metal oxide.

\section{Introduction.}

The development of conjugated polymers (CPs) was very active in the last decades with the discovery of their electrical conductivity and their use in optoelectronic devices such as polymer solar cells (PSCs)[1], organic field effect transistors (OFETs)[2] or photodetectors (PPDs)[3]. In the field of PSCs, the improvement of the active layer efficiency was the topic of intensive research.[4] The bulk heterojunction is based on the blend of electron donors (conjugated polymers) and electron acceptors. Within the electron donors, low band-gap (LBG) conjugated polymers have nowadays outperformed classical CPs thanks to their well-localized absorption in the solar spectrum due to a bandgap smaller than $1.6 \mathrm{eV}$ and their number of delocalized $\pi$ electrons.[5] Their ability to harvest more photons than classical CPs comes from their chemical structure made of an alternation of two co-monomers, an electron-rich monomer, which produces a rise of the polymer HOMO energy level and an electron-deficient monomer inducing a lowering of the polymer LUMO energy level. Concerning electron acceptors, fullerene derivatives showed limited stability and challenges recently emerged.[6,7] Among them, metal oxide nanoparticles, especially titanium dioxide $\mathrm{TiO}_{2}$ and zinc oxide $\mathrm{ZnO}[8]$, are studied because of their low toxicity (unlike cadmium selenium) and the possibility of tailoring their electronic properties by doping or changing their morphologies and dimensions.[8] Therefore hybrid solar cells, composed of a bulk heterojunction between an inorganic material as an acceptor and a conjugated polymer as a donor matrix, came out. $[9,10]$

Recently, hybrid materials based on conjugated polymers were successfully developed in which the macromolecules were covalently attached to the surface of an inorganic material.[11] These novel materials raised promises of enhanced interfacial properties[12,13] with the optimization of particles dispersion, charge injection or transport.[14-16] Pioneering studies showed the potential of these technologies in photovoltaics but their performances are limited by the difficulty of the hybrid material synthesis.[17-21] Indeed, most of the inorganics are grafted with the well-known poly(3-hexylthiophene) because its polymerization is based on a chain-growth mechanism, allowing an easy end-capping[22] with anchoring functions such as silane, thiols or carboxylic 
acids.[23-26] On the contrary, LBG polymers are synthesized via a step-growth mechanism and their end-functionalization is more challenging and reports are scarce.[27-30] In a previous publication, we reported the use of surface initiated polycondensation to grow low band-gap polymers brushes from of metal oxide nanorods.[31] By using this technique, a high polymer grafting density has been obtained with a homogeneous polymer corona surrounding the inorganic core. Actually, this is not the ideal morphology for photovoltaic application since it hinders electron percolation between acceptor domains (particle cores).[11]

Therefore, an effort has been made in this study to reduce the grafting density in order to obtain patchy particles in which both polymer and metal oxide surfaces can be reached by electron and hole. This paper describes a methodology to end-functionalize low band-gap polymers with triethoxysilane or catechol groups in order to bind metal oxide surfaces (Scheme 1). These functions have been inserted at the end of the poly[(4,4'-bis(2-ethylhexyl)dithieno-[3,2-b:2',3'd] silole)-2,6-diyl-alt-(2,1,3-benzothiadiazole)-4,7-diyl] P(DTS-BT) by using a ternary blend of co-monomers in the polycondensation media. The influence of the end-capper quantity on the molar mass and the chain functionality is described. Then, polymer chains were grafted, to create an organic corona around the zinc oxide nanoparticles (NPs). Synthesis, morphological and electronic properties are finally discussed.

\section{Scheme 1.}

\section{Experimental Part}

\subsection{Materials.}

All reactions were performed under pre-dried nitrogen using flame-dried glassware and conventional Schlenk tube techniques. Syringes used to transfer reagents or solvents were purged with nitrogen prior use. Chemicals and reagents were used as received from Aldrich (France) and stored in the glove box. Solvents (Aldrich, France) were used as received.

\subsection{Physico-chemical characterization.}


${ }^{1} \mathrm{H}$ Nuclear Magnetic Resonance (NMR) spectra were recorded using a Bruker $400 \mathrm{MHz}$ instrument in $\mathrm{CDCl}_{3}$ at ambient temperature. Size Exclusion Chromatography (SEC) was performed using a bank of 4 columns (Shodex KF801, 802.5, 804 and 806) each $300 \mathrm{~mm} \times 8 \mathrm{~mm}$ at $30{ }^{\circ} \mathrm{C}$ with THF eluent at a flow rate of $1.0 \mathrm{ml} \cdot \mathrm{min}^{-1}$ controlled by a Malvern pump (Viskotek, VE1122) and connected to Malvern VE3580 refractive index (RI) and Malvern VE3210 UVVisible detectors. Calibration was performed against polystyrene standards. UV-visible absorption spectra were recorded on a Shimadzu UV-2450PC spectrophotometer. Thermal gravimetric analysis (TGA) was performed on a TGA Q50, TA Instruments at a heating rate of $10{ }^{\circ} \mathrm{C} \cdot \mathrm{min}^{-1}$ under nitrogen. Emission Spectroscopy (Photoluminescence): Corrected steady-state emission and excitation spectra were recorded at $2 \mathrm{~nm}$ resolution using a photon counting Edinburgh FLS920 fluorescence spectrometer with a xenon lamp. Concentrations in $\mathrm{CHCl}_{3}$ were adjusted to an absorbance around 0.1 at $670 \mathrm{~nm}$ (excitation wavelength) in a $1 \mathrm{~cm}$ quartz fluorescence cell (Hellma). Electron Microscopy (TEM) images were obtained with a TEM $1400 \mathrm{JEOL}$ at $120 \mathrm{kV}$, HR TEM images were obtained with a JEOL JEM 2200FS FEG HR $200 \mathrm{kV}$.

\subsection{Synthesis}

General Synthesis of End-Functional Conjugated Polymer P(DTS-BT)-End-cap. 4,4'-bis(2ethylhexyl)-5,5'-bis(trimethyltin)-dithieno[3,2-b:2',3'-d]silole monomer DTS (1 eq.), 4,7dibromo-2,1,3-benzothiadiazole monomer BT (0.96 eq.), end-capping unit either 4-bromostyrene or 4-bromoveratrole (0.08 eq.), tris(dibenzylideneacetone)dipalladium( 0$)\left(\mathrm{Pd}_{2} \mathrm{dba}\right)(0.02$ eq.), and tri(o-tolyl)phosphine $\left(\mathrm{P}(o \text {-tol })_{3}\right)(0.1$ eq. $)$ were accurately weighed into a $10 \mathrm{~mL}$ Biotage microwave vial equipped with a PTFE magnetic stirrer. The reaction vial was brought into a nitrogen-filled glovebox and dry chlorobenzene $(2.0 \mathrm{~mL})$ was added. Afterwards, the vial was securely sealed with a septum and removed from the glovebox. The vial was placed into an oil bath and stirred for 6 hours at $140{ }^{\circ} \mathrm{C}$. After cooling, the polymer was precipitated in methanol (200 mL), filtered in a Soxhlet thimble, washed by Soxhlet extraction using ethanol and recovered with chloroform. The polymer was dried under vacuum to afford a dark blue solid, with a yield of $66 \%$.

${ }^{1} \mathrm{H}$ NMR P(DTS-BT)-BrS ( $\delta$ ppm, $\left.\mathrm{CDCl}_{3}\right): 8.26-7.76(\mathrm{~m}, 28 \mathrm{H}), 6.73(\mathrm{q}, 1 \mathrm{H}), 5.78(\mathrm{~d}, 1 \mathrm{H}), 5.26$ $(\mathrm{d}, 1 \mathrm{H}), 1.46-0.7(\mathrm{~m}, 238 \mathrm{H})$ 
${ }^{1} \mathrm{H}$ NMR P(DTS-BT)-BrV $\left(\delta \mathrm{ppm}, \mathrm{CDCl}_{3}\right): 8.26-7.76(\mathrm{~m}, 28 \mathrm{H}), 4.0-3.8(\mathrm{~m}, 6 \mathrm{H}), 1.46-0.7(\mathrm{~m}$, $238 \mathrm{H})$.

General Synthesis of triethoxysilane-terminated P(DTS-BT)-Si. In flame-dried $50 \mathrm{~mL}$ flask, $40 \mathrm{mg}$ of $\mathrm{P}(\mathrm{DTS}-\mathrm{BT})-\mathrm{BrS}$ (2 eq.) was mixed with $2.6 \mathrm{mg}$ of $\mathrm{H}_{2} \mathrm{PtCl}_{6}$ (catalyst, $1 \mathrm{eq}$ ) and $15 \mathrm{~mL}$ of $\mathrm{CHCl}_{3}$. The solution mixture was degassed for $15 \mathrm{~min}$ to avoid oxygen. Under stirring, $0.2 \mathrm{~mL}$ (0.170 g, 200 eq.) of triethoxysilane was added drop wise. The mixture was stirred for $30 \mathrm{~min}$ at room temperature before the temperature was raised to $55^{\circ} \mathrm{C}$ for $5 \mathrm{~h}$. Finally, the polymer was precipitated in dry ethanol, filtered under nitrogen and stored in the glove box to avoid hydrolysis/condensation of the polymer end-chain. Yield $=88 \%$. ${ }^{1} \mathrm{H}$ NMR (ppm, $\left.\mathrm{CDCl}_{3}\right): 8.26$ $7.26(\mathrm{~m}, 4 \mathrm{H}), 3.86(\mathrm{~s}, 6 \mathrm{H}), 2.67(\mathrm{t}, 1 \mathrm{H}), 1.46-0.7(\mathrm{~m}, 249 \mathrm{H})$.

General Synthesis of the catechol-terminated P(DTS-BT)-Cat. In a flame-dried $250 \mathrm{~mL}$ flask, $100 \mathrm{mg}$ of P(DTS-BT)-BrV (1 eq.) was mixed with $75 \mathrm{~mL}$ of dried $\mathrm{CHCl}_{3}$. The flask was placed into an ethanol/nitrogen bath at $-40{ }^{\circ} \mathrm{C}$ during $15 \mathrm{~min}$ to allow a good solubilization. Under stirring, $0.2 \mathrm{~mL}$ ( $0.313 \mathrm{~g}, 50$ eq.) of boron tribromide was added drop wise. The mixture was allowed to go back to room temperature and stirred for $24 \mathrm{~h}$ at room temperature. Then, the flask was placed into an ice bath at $0{ }^{\circ} \mathrm{C}$ and $12.5 \mathrm{~mL}$ of distilled water were added to the mixture. The mixture was stirred for $12 \mathrm{~h}$ at room temperature under vigorous stirring. The solution was concentrated under reduced pressure and the polymer was precipitated in $\mathrm{MeOH}(400 \mathrm{~mL})$, filtered and stored in the glove-box to avoid hydrolysis/condensation of the polymer end-chain. Yield $=80 \%$.

ZnO NPs synthesis. The ZnO nanoparticles synthesis method was adapted from Seow et al. [45] Briefly, zinc acetate dihydrate $(0.87 \mathrm{~g}, 3.35 \mathrm{mmol})$ was first dissolved in methanol $(31.25 \mathrm{~mL})$ while a methanolic potassium hydroxide solution was prepared by dissolving potassium hydroxide $(0.37 \mathrm{~g}, 6.59 \mathrm{mmol})$ in $16.25 \mathrm{~mL}$ of methanol. This potassium hydroxide solution was added dropwise under vigorous stirring into the zinc acetate solution, pre-heated to $60^{\circ} \mathrm{C}$. After $1.5 \mathrm{~h}$, the NPs started to precipitate leading to a turbid solution, which was maintained as such for 2 more hours. The heater and stirrer were then removed and the solution was allowed to stand at room temperature for another $2 \mathrm{~h}$. The $\mathrm{ZnO}$ nanoparticles settled at the bottom; the supernatant was removed and the precipitate was collected by centrifugation at $9000 \mathrm{rpm}$ with methanol for $20 \mathrm{~min}$. and washed 3 times with methanol. The precipitate was then dispersed in $12.5 \mathrm{~mL}$ of methanol and $2.5 \mathrm{ml}$ of chloroform. 
General procedure for grafting P(DTS-BT) onto ZnO NPs. ZnO NPs were dispersed in $\mathrm{CHCl}_{3}$ ( $2 \mathrm{mg} . \mathrm{mL}^{-1}, 12 \mathrm{~mL}$ ) by ultrasonication for $1 \mathrm{~h} .2 \mathrm{~mL}$ solution of polymer P(DTS-BT) terminated with triethoxysilane or catechol $\left(17.7 \mathrm{mg} \cdot \mathrm{mL}^{-1}\right)$ in $\mathrm{CHCl}_{3}$ was added to the mixture. From the $\mathrm{ZnO}$ NPs specific surface area (SSA), we calculated that P(DTS-BT) was introduced at $1 \mathrm{chain} / \mathrm{nm}^{2}$ of $\mathrm{ZnO}$ surface in order to not saturate the surface. The ungrafted or free chains were removed at the end of the reaction by solubilizations and washings. The reaction then proceeded at $60{ }^{\circ} \mathrm{C}$ for $10 \mathrm{~h}$ under inert atmosphere. The medium was cooled to room temperature and ZnO@P(DTS-BT) was purified by centrifugation $\left(10,000 \mathrm{rpm}, 10 \mathrm{~min}, 15^{\circ} \mathrm{C}\right)$ with removal of the supernatant containing excess of organic component. The purification was repeated several times until the UV-visible spectra of the $\mathrm{CHCl}_{3}$ supernatant became featureless (no P(DTS-BT) absorption around $670 \mathrm{~nm}$ ). The precipitated particles were collected, dried and stored under nitrogen. A change in the color of the $\mathrm{ZnO}$ NPs was clearly observable from white to blue after grafting of P(DTS-BT) (dry state).

\section{Results and discussion}

\subsection{Synthesis of end-functional low band-gap polymers.}

In this study, 4,7-dibromo-2,1,3-benzothiadiazole (BT) and 4,4'-bis(2-ethyl-hexyl)-5,5'bis(trimethyltin)-dithieno[3,2-b:2',3'-d]silole (DTS) were polymerized via a Stille cross-coupling reaction, using $\mathrm{Pd}^{0}$ catalyst and 4-bromostyrene as an end-capper (monofunctional) to synthesize a vinyl end-functionalized polymer. This polymer was chosen for its broad absorption, high hole mobility, good photochemical stability and a reasonable power conversion efficiency of 5.1\%.[32] Monomers were obtained with high purity (synthesis and characterization in the Supporting Information, SI1). 4-bromostyrene was selected as an appropriate end-capper due to its Stille polymerizable bromophenyl group and the presence of the alkene allowing unambiguous characterization of the resulting end-functional material. In this kind of reaction, the stoichiometry of monomer to end-capping unit is a key factor that determines the length of the chain and the degree of end-group introduction. In this paper, the stoichiometry of the reagents was maintained according to the equation 1 :

$\mathrm{N}_{\mathrm{A}}=\mathrm{N}_{\mathrm{B}}+\mathrm{N}_{\mathrm{B}}, \quad \rightarrow \quad 2 N_{D T S}=2 N_{B T}+N_{E G}$ 
In which $\mathrm{N}_{\mathrm{A}}, \mathrm{N}_{\mathrm{B}}, \mathrm{N}_{\mathrm{B}}$, represent the mole number of stannate functions and bromide groups pertaining to the BT monomer and to the end-capping agent respectively. $\mathrm{N}_{\mathrm{DTS}}, \mathrm{N}_{\mathrm{BT}}$ and $\mathrm{N}_{\mathrm{EG}}$, define the mole number of DTS and BT monomers and bromostyrene end-groups (EG), respectively. By following this stoichiometry, the total number of aryl bromides is equal to the total number of aryl stannanes and the formation of chains bearing 4-bromostyrene is promoted. The number average degree of polymerization $\left(D P_{n}\right)$ of polymers obtained in the case of an A-A and B-B polycondensation, like DTS and BT, with an end-capper agent, can be predicted thanks to the Carothers equation (eq 2)[33,34]:

$\overline{D P}_{n}=\frac{1+r}{1+r-2 r p}$

In which $r$ is the ratio of monomer groups, and $p$ is the conversion. It should be noted that in this equation, DPn counts the number of DTS + BT units, so it is twice the number of repeat units $n$ used in the calculation of the number average molecular weight $\mathrm{Mn}$. Therefore, $\mathrm{Mn}$ can be calculated as follows:

$\bar{M}_{n}=M_{0} \frac{\overline{D P n}}{2}=\frac{M_{0}}{2} \frac{1+r}{1+r-2 r p}$

Where $M_{0}$ is the molecular weights of the repeat unit. When monofonctional reagent (as the endcapping agent) is introduced, the monomer group ratio is defined by the equation 3[35]:

$r=\frac{N_{A}}{N_{B}+2 N_{B \prime}}=\frac{2 N_{D T S}}{2 N_{B T}+2 N_{E G}}=\frac{N_{D T S}}{N_{B T}+N_{E G}}$

Where the factor 2 relative to $\mathrm{N}_{\mathrm{B}}$, enters in the equation because the end-capper reagent has the same effect on the degree of polymerization than a difunctional monomer therefore is two times more effective.

Three end-functional polymers were synthesized in chlorobenzene by varying the initial bromostyrene molar equivalent $\mathrm{N}_{\mathrm{EG}}=0,0.08$ and 0.16 (Table 1). After purification by precipitation and Soxhlet extraction (as indicated in the experimental part), ${ }^{1} \mathrm{H}$ NMR, Sizeexclusion chromatography (SEC) and MALDI-ToF analyses were performed to characterize these polymers. First, we used NMR not only to verify the proton structure of the polymer but also to calculate the ratio between the repetitive units and the end-group ( $\mathrm{n}_{\mathrm{DTSBT}} / \mathrm{n}_{\mathrm{EG}}$, Table 1 ). By 
comparing the integral of the peak at $5.8 \mathrm{ppm}$ corresponding to the vinyl double bond (styrene, $\mathrm{d}$ Figure 1) to the signal from 7.7 to $8.4 \mathrm{ppm}$ referring to the aromatic protons of DTS and BT units (f and $g$ in Figure 1), we estimated this $\mathrm{n}_{\mathrm{DTSBT}} / \mathrm{n}_{\mathrm{EG}}$ ratio in the final polymers. For $\mathrm{P}(\mathrm{DTS}-\mathrm{BT}$ )$\mathrm{BrS}_{(1)}$, which is the polymer synthesized with a bromostyrene $(\mathrm{BrS})$ molar equivalent of 0.08 , this ratio was 7. Thanks to the Carothers equation (2), the theoretical DPn was calculated to be 49 (at $100 \%$ conversion), corresponding to 24 DTS-BT repetitive units. Since bromostyrene has been included in the stoichiometry (equation 1), styrene units should be at both end-chains for a $100 \%$ conversion. Therefore, for this polymer, the theoretical $n_{D T S B T} / n_{E G}$ ratio is 12 (reported in Table 1). The difference between the theory and the experiment may be due to conversion, since a theoretical $98 \%$ conversion leads to a repetitive unit (DTS-BT) to styrene ratio of 7.

\section{Figure 1.}

For $\mathrm{P}(\mathrm{DTS}-\mathrm{BT})-\mathrm{BrS}_{(2)}$, a bromostyrene molar equivalent of 0.16 was used to study the possibility to tune the molar mass of the sample. From the ${ }^{1} \mathrm{H}$ NMR spectrum (Figure SI-2) the DTS$\mathrm{BT} / \mathrm{styrene}$ ratio is decreased to 5 which is really close to the theoretical value of 7 repetitive units given by Carothers equation. If the ratio repeat units by vinyl bonds can be calculated, no information can be provided on the effective number of end-groups per polymer chain.

\section{Table 1.}

Therefore MALDI-ToF analysis was performed and allowed defining and quantifying chain's end-groups. As a technique limitation, only low molar mass chains can be analyzed $(\mathrm{M} \leq 3000$ g.mol ${ }^{-1}$, see Figure SI-3). Figure 2 shows a zoom of the P(DTS-BT)-BrS(2) sample for the populations with a $1900 \leq \mathrm{M} \leq 2500 \mathrm{~g} \cdot \mathrm{mol}^{-1}$. Several populations appeared and it was not possible to assign them all. However, populations with abundance higher than $10 \%$ were identified. Thus, several information from the mass spectrum can be extracted as the presence of di-capped, mono- 
capped and non-functionalized chains. For example, the assigned peaks with green circle, blue triangle and yellow star have been assigned to non-functionalized, mono-capped and end-capped chains, respectively, on the basis of the styrene molar mass difference. From the overall MALDIToF spectrum, a quantification of each population can be estimated with $28 \%$ of difunctionalized $\alpha, \omega$-styrene chains, $47 \%$ of mono-functionalized and $25 \%$ of nonfunctionalized. Therefore, a total of $75 \%$ of the chains were styrene end-capped, in agreement with the ${ }^{1} \mathrm{H}$ NMR spectrum showing that the conversion was not total. Moreover, some DTS homocoupling was detected as already shown by Harris et al..[30]

\section{Figure 2.}

Size exclusion chromatography was performed on both polymers (figure SI-4) and reasonable dispersity values around $Đ=2$ were obtained. $M n$ and $M w$ from 4000 to 9200 g.mol-1 were calculated from conventional calibration using polystyrene samples. Using UV-visible spectrophotometry, the maximum absorption was found at $680 \mathrm{~nm}$ and the optical band gap evaluated at $1.51 \mathrm{eV}$ (estimated from the low energy band edge of the optical spectrum, $\lambda_{\text {onset }}=$ $820 \mathrm{~nm}, \mathrm{Eg}=1240 / \lambda_{\text {onset }} \mathrm{eV}$, Figure SI-5). Comparison of absorption spectra with literature confirmed that the degree of polymerization was high enough to reach the maximum conjugation length.[36]

A further post-functionalization via the hydrosilylation of the vinyl moiety was performed under dry conditions to modify the alkene into a triethoxysilane end-group in quantitative yields. This group is well known to react by hydrolysis-condensation with hydroxyl surface functions of metal oxide materials. ${ }^{1} \mathrm{H}$ NMR (figure SI-6) was used to follow the conversion of the alkene to the triethoxysilane function. Triethoxysilane-terminated P(DTS-BT) (named P(DTS-BT)-Si from now on) spectrum showed a complete disappearance of the alkene protons in the 5.00- $6.00 \mathrm{ppm}$ range 
as well as the appearance of a peak at 3.86 ppm corresponding to the $\mathrm{O}-\mathrm{CH}_{2}$ of the silane endchain. Due to the high sensitivity of the Si-OEt moiety to hydrolysis, the silane end-functionalized polymers (Si-P(DTS-BT)) were stored in a glove box under inert atmosphere.

Following the exact same strategy of ternary blend, we functionalized P(DTS-BT) with the second end-capper, the 4-bromoveratrole (P(DTS-BT)-BrV, see scheme 1. The same characterization techniques were applied to this polymer. ${ }^{1} \mathrm{H}$ NMR spectrum in Figure $1 \mathrm{~b}$ shows in addition to the peaks assigned to the polymer, a peak at 4 ppm characteristic of the $\mathrm{CH}_{3}$ of the 4-bromoveratrole. The ratio of repetitive unit/end-capper was determined to be 7 , very close to the theoretical value of 9 (Figure 1 and Table 1). This end-group is of great interest because methoxy groups can easily be deprotected to a catechol moiety which is then used to bind on metal oxide surfaces (named Cat-P(DTS-BT) from now on).[37,38]

\subsection{Grafting of $P(D T S-B T)$ on the surface of zinc oxide nanoparticles.}

The spherical $\mathrm{ZnO}$ nanoparticles (NPs) (diameter $=20 \mathrm{~nm}$ ) were dispersed in $\mathrm{CHCl}_{3}$ and mixed with an excess of silane terminated polymer $\left(1\right.$ chain $\left./ \mathrm{nm}^{2}\right)$. The blend was heated at $60^{\circ} \mathrm{C}$ under vigorous stirring during 10 hours. Then the NPs were washed from the unreacted polymer by several dispersion-centrifugation cycles in chloroform until the UV-visible spectrum of the supernatant was clear of any polymer absorption. These core@ shell NPs (named ZnO@Si-P(DTSBT) and ZnO@Cat-P(DTS-BT)) were characterized by thermal gravimetric analysis (TGA) under nitrogen with a heating rate of $10{ }^{\circ} \mathrm{C} \cdot \mathrm{min}^{-1}$ in order to follow the thermal degradation of the organic part and quantify the amount of P(DTS-BT) covalently linked to the NPs (Figure 3). The bare ZnO NPs showed a weight loss of $0.95 \%$ between 100 and $550{ }^{\circ} \mathrm{C}$ corresponding to the loss of remaining chemically adsorbed water, while for pure P(DTS-BT) a weight loss of about $42 \%$ was observed between 350 and $550^{\circ} \mathrm{C}$. Figure 3 shows that the overall weight losses for the two hybrid materials, ZnO@Si-P(DTS-BT) and ZnO@Cat-P(DTS-BT), were $7.4 \%$ and $2.2 \%$, respectively. From these values and by using the following formula:

$$
\text { weight } \% \text { grafted } P(D T S-B T)=\frac{(\text { weight loss ZnO@PDTSBT })-(\text { weight loss bare } Z n O)}{\text { weight loss of } P(D T S-B T)} \times 100
$$


the weight percentage of the polymer brushes in the hybrid was calculated to be $15.4 \%$ and $3 \%$ for ZnO@Si-P(DTS-BT) and ZnO@Cat-P(DTS-BT), respectively.

\section{Figure 3.}

TEM was used to observe the morphology of the hybrid materials and evaluate the thickness of the grafted P(DTS-BT) layer onto the ZnO NPs surface. Figure 4a presents the image of bare zinc oxide spherical nanoparticles with a particle diameter of $20 \pm 5 \mathrm{~nm}$ (cf. size distribution in SI Figure SI-7). In Figure $4 b$ the image of the ZnO@Si-P(DTS-BT) is shown. Aggregates of few hundreds nanometers can be observed in low magnification picture (see supporting information Figure SI-8) and at higher magnification, inside the aggregates the particles seemed embedded in the polymer matrix. Indeed, despite dilution, agitation or sonication we could not observe proper images of isolated nanoparticles and only aggregates were obtained. Zinc oxide particles seemed to be embedded in a polymer matrix.Repetition It is well-known in literature that the triethoxysilane group, with a functionality of three, can self-condensate upon hydrolysis leading to the formation of multilayers(Figure 4b) or crosslinked materials.[39,40] Moreover, in the synthesized macromolecules, as shown by MALDI-ToF, $28 \%$ of the chains bear a silane function at both ends. Therefore, during the grafting step, a crosslinking of polymer chains occurs, hence forming a matrix around the inorganic particles. This phenomenon is concomitant with their anchoring on the surface of the particles (see more pictures in supporting information Figures SI9 to 11). On the contrary, when catechol end-terminal chains were used to graft zinc oxide particles, the TEM images in Figures $4 \mathrm{c}$ and d show a $3 \pm 1 \mathrm{~nm}$ thick organic layer around the NPs without crosslinking. Isolated particles bearing a heterogeneous polymer layer can easily be seen in the pictures. Indeed, on the TEM images, the polymer layer (light grey), does not completely cover the dark grey zinc oxide nanoparticles. Thus patchy particles are obtained with a majority of the zinc oxide surface covered with polymer chains. This heterogeneity is of great interest in photovoltaic applications where both good dispersion and electron percolation between inorganic acceptor particles are targeted. 


\section{Figure 4.}

The nanoparticles specific surface area (SSA) was calculated to $53 \mathrm{~m}^{2} \cdot \mathrm{g}^{-1}$ (calculation in supporting information). Since the weight fraction of P(DTS-BT) $\left(f_{\mathrm{w}} \mathrm{P}(\mathrm{DTS}-\mathrm{BT})\right)$ was extracted from TGA, the surface grafting density $(\sigma)$ of the polymer was calculated via the equation:

$$
\sigma=\frac{\frac{f_{W P(D T S-B T)}}{1-f_{W P(D T S-B T)}} \times N_{A v}}{\overline{M n} \times S S A} \quad \text { where } N_{A v} \text { is the Avogadro constant }
$$

$\mathrm{ZnO} @$ Si-P(DTS-BT) exhibits crosslinking, thus it would be a nonsense to calculate a grafting density, but for the $\mathrm{ZnO} @$ Cat-P(DTS-BT) samples, the grafting density is 0.05 chain $/ \mathrm{nm}^{2}$, corresponding to 60 polymer chains per $\mathrm{ZnO}$ NP. This value is typically associated to polymer brushes in the "mushroom" regime, in which the space between grafted molecules is higher than two times the gyration radius of the polymer chain.[41] This low grafting density could be explained by the volume of the macromolecular grafting agent, which produces a high steric hindrance at the metal oxide surface during the immobilization procedure. Since TEM images showed that the grafting is heterogeneous, therefore there are some areas on the particles where the chain density is lower than the average 0.05 chain per $\mathrm{nm}$ and others where the density is higher.

\subsection{Photophysics of the hybrid nanoparticles.}

The core@shell nanoparticles were then characterized by UV-visible absorption and photoluminescence (PL). Figure 5a presents the absorption spectra of pure polymer P(DTS-BT), the grafted ZnO@P(DTS-BT) and a mixture of bare ZnO with P(DTS-BT). In this last case, the ratio of the two components was calculated to match the mass ratio found by TGA for the grafted NPs. Therefore, the absorbance of the mixture and the hybrid ZnO@P(DTS-BT) should match and especially the maxima of absorbance at $680 \mathrm{~nm}$ and $370 \mathrm{~nm}$ for the polymer and the ZnO NPs, respectively. The comparison between the mixture and the hybrid absorption spectra revealed an increase of the absorption intensity at $750 \mathrm{~nm}$ when the polymer is covalently linked to the nanoparticle. This effect has been previously reported in the literature by Kiriy's group with P3HT functionalized silica particles and was attributed to the establishment of $\pi$ - $\pi$ interactions due to the 
proximity of anchored polymer chains.[42] The same bathochromic effect is well known in conjugated polymer films. Moreover, the maximum at $369 \mathrm{~nm}$, characteristic of ZnO NPs (present in the $\mathrm{ZnO}$ /polymer physical mixture) exhibits a discernible blue shift of about $6 \mathrm{~nm}$ in the case of $\mathrm{ZnO} @ \mathrm{P}(\mathrm{DTS}-\mathrm{BT})$ spectrum. This is due to variation in the dielectric environment of the oxide surface by the grafted macromolecules.[43] In a previous publication, our group reported the anchoring of this polymer on zinc oxide nanorods by surface initiated polymerization. The same features with a maximum at $680 \mathrm{~nm}$ and a shoulder at $750 \mathrm{~nm}$ were observed.[31]

Figure $5 \mathrm{~b}$ presents the PL spectra of the polymer, the blend polymer/bare $\mathrm{ZnO}$ particles and the $\mathrm{ZnO} @ \mathrm{P}(\mathrm{DTS}-\mathrm{BT})$, under an incident light of $\lambda=670 \mathrm{~nm}$ (Figure SI-12 shows the corresponding excitation spectra). Since the HOMO/LUMO levels of the polymer and the $\mathrm{ZnO}$ have already been reported at -5.25/-3.45 espectively. 10.1016/j.eurpolymj.2013.09.025 The main signal of the polymer spectrum from 700 to $830 \mathrm{~nm}$ is a typical emission of the P(DTS-BT) backbone that arises from the relaxation of excited $\pi$-electrons to the ground state. When the physical blend was analyzed, the PL intensity remained the same, meaning that no energy transfer occurred from the polymer to the nanoparticles. The main explanation for this behavior is that the concentration of the materials in chloroform is too low to induce an interaction. However, in comparison, the photoluminescence of the core@shell particles was drastically quenched. Indeed, the intimacy of the hybrid components allows the electron transfer from polymer to zinc oxide. [44]

\section{Figure 5.}

\section{Conclusion}

The use of a ternary blend of co-monomers is an efficient methodology to synthesize endfunctional low band-gap polymers bearing surface anchoring groups. Triethoxysilane and catechol terminated macromolecules were successfully obtained and ${ }^{1} \mathrm{H}$ NMR and MALDI-ToF techniques were used to identify and quantify the end-functionality. Importantly, and in agreement with the theory, the amount of mono-functional monomer (styrene or bromoveratrole) controls the chains molar mass. $\mathrm{ZnO}$ spherical nanoparticles were then grafted by the polymer chains and TEM confirmed that hybrid materials were formed. The surface morphology of the hybrid materials was 
anchoring agent dependent. When silane functionalized polymers are used, cross-linked aggregates made of NPs embedded in a matrix are obtained due to the competition between selfcondensation of silanes and reaction with $\mathrm{ZnO}$ surface hydroxyl groups. On the contrary, welldispersed core-shell particles were synthesized with catechol polymer as anchoring agent. The grafting onto methodology led to patchy nanoparticles with partial coverage on which both zinc oxide and polymer surfaces are accessible. Photoelectronic characterizations were conducted on these hybrid materials and showed absorption features that are not present on polymer/particle physical mixture, thus proving specific interactions between the core and the shell. Finally, photoluminescence revealed the potential of these functionalized particles for photovoltaics with a remarkable quenching of the polymer fluorescence by zinc oxide NPs.

\section{Acknowledgment}

This work was supported by the University of Pau and Pays de l'Adour and developed in the framework of the SMOLED project (Conseil Régional Aquitaine). Virginie Pellerin, Sylvain Chambon and Abdel Khoukh are greatly acknowledged for their involvement in the project, and Jerome Majimel (ICMCB) for his help with HR-TEM. All the TEM observations were performed on the microscopes of the Plateforme Aquitaine de Caractérisation des Matériaux (UMS 3626, CNRS - Univ. de Bordeaux, Pessac, France).

\section{Associated Content}

Experimental procedures and additional figures such as TEM images, thermogravimetric analysis and UV spectra are supplied in Supporting Information.

\section{Data availability}

The raw/processed data required to reproduce these findings cannot be shared at this time due to technical or time limitations. 


\section{References}

[1] C. Cui, Y. Li, High-performance conjugated polymer donor materials for polymer solar cells with narrow-bandgap nonfullerene acceptors, Energy Environ. Sci. 12 (2019) 3225-3246. https://doi.org/10.1039/C9EE02531F.

[2] J. Yang, Z. Zhao, S. Wang, Y. Guo, Y. Liu, Insight into High-Performance Conjugated Polymers for Organic Field-Effect Transistors, Chem. 4 (2018) 2748-2785. https://doi.org/10.1016/j.chempr.2018.08.005.

[3] Y. Xu, Q. Lin, Photodetectors based on solution-processable semiconductors: Recent advances and perspectives, Appl. Phys. Rev. 7 (2020) 011315. https://doi.org/10.1063/1.5144840.

[4] J. Nelson, Polymer:fullerene bulk heterojunction solar cells, Mater. Today. 14 (2011) 462470. https://doi.org/10.1016/S1369-7021(11)70210-3.

[5] C. Liu, K. Wang, X. Gong, A.J. Heeger, Low bandgap semiconducting polymers for polymeric photovoltaics, Chem. Soc. Rev. 45 (2016) 4825-4846. https://doi.org/10.1039/C5CS00650C.

[6] S. Bertho, G. Janssen, T.J. Cleij, B. Conings, W. Moons, A. Gadisa, J. D’Haen, E. Goovaerts, L. Lutsen, J. Manca, D. Vanderzande, Effect of temperature on the morphological and photovoltaic stability of bulk heterojunction polymer:fullerene solar cells, Sol. Energy Mater. Sol. Cells. 92 (2008) 753-760. https://doi.org/10.1016/j.solmat.2008.01.006.

[7] Y. Liu, J. Zhao, Z. Li, C. Mu, W. Ma, H. Hu, K. Jiang, H. Lin, H. Ade, H. Yan, Aggregation and morphology control enables multiple cases of high-efficiency polymer solar cells, Nat. Commun. 5 (2014). https://doi.org/10.1038/ncomms6293.

[8] J. Bouclé, P. Ravirajan, J. Nelson, Hybrid polymer-metal oxide thin films for photovoltaic applications, J. Mater. Chem. 17 (2007) 3141. https://doi.org/10.1039/b706547g.

[9] T. Xu, Q. Qiao, Conjugated polymer-inorganic semiconductor hybrid solar cells, Energy Environ. Sci. 4 (2011) 2700. https://doi.org/10.1039/c0ee00632g.

[10] W.J.E. Beek, M.M. Wienk, R.A.J. Janssen, Efficient Hybrid Solar Cells from Zinc Oxide Nanoparticles and a Conjugated Polymer, Adv. Mater. 16 (2004) 1009-1013. https://doi.org/10.1002/adma.200306659.

[11] A. Bousquet, H. Awada, R.C. Hiorns, C. Dagron-Lartigau, L. Billon, Conjugated-polymer grafting on inorganic and organic substrates: A new trend in organic electronic materials, 
$\begin{array}{lllll}\text { Prog. } & \text { Polym. } & \text { Sci. } & 39 & \text { (2014) }\end{array}$ https://doi.org/10.1016/j.progpolymsci.2014.03.003.

[12] L. Miozzo, A. Yassar, G. Horowitz, Surface engineering for high performance organic electronic devices: the chemical approach, J. Mater. Chem. 20 (2010) 2513. https://doi.org/10.1039/b922385a.

[13] H. Ma, H.-L. Yip, F. Huang, A.K.-Y. Jen, Interface Engineering for Organic Electronics, Adv. Funct. Mater. 20 (2010) 1371-1388. https://doi.org/10.1002/adfm.200902236.

[14] H. Ishii, K. Sugiyama, E. Ito, K. Seki, Energy Level Alignment and Interfacial Electronic Structures at Organic/Metal and Organic/Organic Interfaces, Adv. Mater. 11 (1999) 605625. https://doi.org/10.1002/(SICI)1521-4095(199906)11:8<605::AIDADMA605>3.0.CO;2-Q.

[15] J.J. Gooding, S. Ciampi, The molecular level modification of surfaces: from self-assembled monolayers to complex molecular assemblies, Chem. Soc. Rev. 40 (2011) 2704. https://doi.org/10.1039/c0cs00139b.

[16] A. Tada, Y. Geng, M. Nakamura, Q. Wei, K. Hashimoto, K. Tajima, Interfacial modification of organic photovoltaic devices by molecular self-organization, Phys. Chem. Chem. Phys. 14 (2012) 3713. https://doi.org/10.1039/c2cp40198c.

[17] M.D. Goodman, J. Xu, J. Wang, Z. Lin, Semiconductor Conjugated Polymer-Quantum Dot Nanocomposites at the Air/Water Interface and Their Photovoltaic Performance, Chem. Mater. 21 (2009) 934-938. https://doi.org/10.1021/cm803248j.

[18] F. Li, Y. Du, Y. Chen, L. Chen, J. Zhao, P. Wang, Direct application of P3HT-DOPO@ZnO nanocomposites in hybrid bulk heterojunction solar cells via grafting P3HT onto $\mathrm{ZnO}$ nanoparticles, Sol. Energy Mater. Sol. Cells. $97 \quad$ (2012) 64-70. https://doi.org/10.1016/j.solmat.2011.09.002.

[19] J. Jung, Y.J. Yoon, Z. Lin, Semiconducting organic-inorganic nanocomposites by intimately tethering conjugated polymers to inorganic tetrapods, Nanoscale. 8 (2016) 8887-8898. https://doi.org/10.1039/C6NR00269B.

[20] H. Geng, M. Wang, S. Han, R. Peng, Enhanced performance of hybrid photovoltaic devices via surface-modifying metal oxides with conjugated polymer, Sol. Energy Mater. Sol. Cells. 94 (2010) 547-553. https://doi.org/10.1016/j.solmat.2009.11.022. 
[21] H.-C. Chen, C.-W. Lai, I.-C. Wu, H.-R. Pan, I.-W.P. Chen, Y.-K. Peng, C.-L. Liu, C.- hsien Chen, P.-T. Chou, Enhanced Performance and Air Stability of 3.2\% Hybrid Solar Cells: How the Functional Polymer and CdTe Nanostructure Boost the Solar Cell Efficiency, Adv. Mater. 23 (2011) 5451-5455. https://doi.org/10.1002/adma.201102775.

[22] N.V. Handa, A.V. Serrano, M.J. Robb, C.J. Hawker, Exploring the synthesis and impact of end-functional poly(3-hexylthiophene), J. Polym. Sci. Part Polym. Chem. 53 (2015) 831841. https://doi.org/10.1002/pola.27522.

[23] D. Lee, D.-J. Jang, Charge-carrier relaxation dynamics of poly(3-hexylthiophene)-coated gold hybrid nanoparticles, Polymer. $55 \quad$ (2014) 5469-5476. https://doi.org/10.1016/j.polymer.2014.08.069.

[24] H. Awada, H. Medlej, S. Blanc, M.-H. Delville, R.C. Hiorns, A. Bousquet, C. DagronLartigau, L. Billon, Versatile functional poly(3-hexylthiophene) for hybrid particles synthesis by the grafting onto technique: Core@ shell ZnO nanorods, J. Polym. Sci. Part Polym. Chem. 52 (2014) 30-38. https://doi.org/10.1002/pola.26964.

[25] H. Awada, L. Mezzasalma, S. Blanc, D. Flahaut, C. Dagron-Lartigau, J. Lyskawa, P. Woisel, A. Bousquet, L. Billon, Biomimetic Mussel Adhesive Inspired Anchor to Design ZnO@Poly(3-Hexylthiophene) Hybrid Core@Corona Nanoparticles, Macromol. Rapid Commun. 36 (2015) 1486-1491. https://doi.org/10.1002/marc.201500184.

[26] F. Boon, S. Desbief, L. Cutaia, O. Douhéret, A. Minoia, B. Ruelle, S. Clément, O. Coulembier, J. Cornil, P. Dubois, R. Lazzaroni, Synthesis and Characterization of Nanocomposites Based on Functional Regioregular Poly(3-hexylthiophene) and Multiwall Carbon Nanotubes, Macromol. Rapid Commun. 31 (2010) 1427-1434. https://doi.org/10.1002/marc.201000183.

[27] L. Wang, Z. Qiao, C. Gao, J. Liu, Z.-G. Zhang, X. Li, Y. Li, H. Wang, End-Capping Effect of Quinoxalino[2,3- $b$ ']porphyrin on Donor-Acceptor Copolymer and Improved Performance of Polymer Solar Cells, Macromolecules. 49 (2016) 3723-3732. https://doi.org/10.1021/acs.macromol.6b00507.

[28] M.J. Robb, D. Montarnal, N.D. Eisenmenger, S.-Y. Ku, M.L. Chabinyc, C.J. Hawker, A OneStep Strategy for End-Functionalized Donor-Acceptor Conjugated Polymers, Macromolecules. 46 (2013) 6431-6438. https://doi.org/10.1021/ma401255d. 
[29] U. Koldemir, S.R. Puniredd, M. Wagner, S. Tongay, T.D. McCarley, G.D. Kamenov, K. Müllen, W. Pisula, J.R. Reynolds, End Capping Does Matter: Enhanced Order and Charge Transport in Conjugated Donor-Acceptor Polymers, Macromolecules. 48 (2015) 6369-6377. https://doi.org/10.1021/acs.macromol.5b01252.

[30] J.D. Harris, K.R. Carter, A one-pot strategy to improve end-capping efficacy in Stille polycondensations, Polym. Chem. 9 (2018) 1132-1138. https://doi.org/10.1039/C7PY01761H.

[31] H. Awada, A. Bousquet, C. Dagron-Lartigau, L. Billon, Surface-initiated polymerization of A-A/B-B type conjugated monomers by palladium-catalyzed Stille polycondensation: towards low band gap polymer brushes, RSC Adv. 5 (2015) 78436-78440. https://doi.org/10.1039/C5RA08027D.

[32] J. Hou, H.-Y. Chen, S. Zhang, G. Li, Y. Yang, Synthesis, Characterization, and Photovoltaic Properties of a Low Band Gap Polymer Based on Silole-Containing Polythiophenes and 2,1,3-Benzothiadiazole, J. Am. Chem. Soc. 130 (2008) 16144-16145. https://doi.org/10.1021/ja806687u.

[33] P.J. Flory, Molecular Size Distribution in Linear Condensation Polymers ${ }^{1}$, J. Am. Chem. Soc. 58 (1936) 1877-1885. https://doi.org/10.1021/ja01301a016.

[34] H. Knoester, Theoretical Derivation of the Molecular Weight Distribution of End-Capped Linear Condensation Polymers, Macromol. Theory Simul. 18 (2009) 61-69. https://doi.org/10.1002/mats.200800062.

(35) Hiemenz, P. C.; Lodge, T. Polymer Chemistry, chapter 2: Step-Growth Poymerization, 2nd ed.; CRC Press: Boca Raton, 2007.

[36] W.J.E. Beek, M.M. Wienk, R.A.J. Janssen, Hybrid Solar Cells from Regioregular Polythiophene and ZnO Nanoparticles, Adv. Funct. Mater. 16 (2006) 1112-1116. https://doi.org/10.1002/adfm.200500573.

[37] E. Faure, C. Falentin-Daudré, C. Jérôme, J. Lyskawa, D. Fournier, P. Woisel, C. Detrembleur, Catechols as versatile platforms in polymer chemistry, Prog. Polym. Sci. 38 (2013) 236-270. https://doi.org/10.1016/j.progpolymsci.2012.06.004.

[38] Q. Ye, F. Zhou, W. Liu, Bioinspired catecholic chemistry for surface modification, Chem. Soc. Rev. 40 (2011) 4244. https://doi.org/10.1039/c1cs15026j.

[39] Z.W. Wicks, ed., Organic coatings: science and technology, 3rd ed, Wiley-Interscience, Hoboken, N.J, 2007. 
[40] G. Tillet, B. Boutevin, B. Ameduri, Chemical reactions of polymer crosslinking and postcrosslinking at room and medium temperature, Prog. Polym. Sci. 36 (2011) 191-217. https://doi.org/10.1016/j.progpolymsci.2010.08.003.

[41] M. Kim, S. Schmitt, J. Choi, J. Krutty, P. Gopalan, From Self-Assembled Monolayers to Coatings: Advances in the Synthesis and Nanobio Applications of Polymer Brushes, Polymers. 7 (2015) 1346-1378. https://doi.org/10.3390/polym7071346.

[42] V. Senkovskyy, R. Tkachov, T. Beryozkina, H. Komber, U. Oertel, M. Horecha, V. Bocharova, M. Stamm, S.A. Gevorgyan, F.C. Krebs, A. Kiriy, "Hairy" Poly(3hexylthiophene) Particles Prepared via Surface-Initiated Kumada Catalyst-Transfer Polycondensation, J. Am. Chem. Soc. 131 (2009) 16445-16453. https://doi.org/10.1021/ja904885w.

[43] J. Xu, J. Wang, M. Mitchell, P. Mukherjee, M. Jeffries-EL, J.W. Petrich, Z. Lin, Organic-Inorganic Nanocomposites via Directly Grafting Conjugated Polymers onto Quantum Dots, J. Am. Chem. Soc. 129 (2007) 12828-12833. https://doi.org/10.1021/ja074133x.

[44] G.F. Malgas, D.E. Motaung, G.H. Mhlongo, S.S. Nkosi, B.W. Mwakikunga, M. Govendor, C.J. Arendse, T.F.G. Muller, The influence of $\mathrm{ZnO}$ nanostructures on the structure, optical and photovoltaic properties of organic materials, Thin Solid Films. 555 (2014) 100-106. https://doi.org/10.1016/j.tsf.2013.08.012.

[45] Z.L.S. Seow, A.S.W. Wong, V. Thavasi, R. Jose, S. Ramakrishna, G.W. Ho, Controlled synthesis and application of $\mathrm{ZnO}$ nanoparticles, nanorods and nanospheres in dye-sensitized solar cells, Nanotechnology. 20 (2009) 045604. https://doi.org/10.1088/09574484/20/4/045604.

\section{Figure captions}

Scheme 1. Synthetic methodology for the end-capping of low band-gap polymers (considering a complete conversion).

Figure 1. ${ }^{1} \mathrm{H}$ NMR spectra of $\mathrm{P}(\mathrm{DTS}-\mathrm{BT})-\mathrm{BrS}_{(1)}$ (a) and $\mathrm{P}(\mathrm{DTS}-\mathrm{BT})-\mathrm{BrV}$ (b) $\left(400 \mathrm{MHz}, \mathrm{CDCl}_{3}\right)$

Figure 2. MALDI-ToF zoom spectra of P(DTS-BT)-BrS $(2)$ for the populations with a $1900 \leq \mathrm{M} \leq$ 2500 g.mol ${ }^{-1}$. 
Figure 3. Thermogravimetric analysis of P(DTS-BT), grafted ZnO@Si-P(DTS-BT) and ZnO@Cat-P(DTS-BT) NPs under nitrogen at a heating rate of $10{ }^{\circ} \mathrm{C} \cdot \mathrm{min}^{-1}$.

Figure 4. TEM images of a) bare ZnO NPs b) ZnO@SiP(DTS-BT) c) and d) ZnO@CatP(DTS$\mathrm{BT})$.

Figure 5. a) UV-visible absorption and b) photoluminescence $\left(\lambda_{\mathrm{ex}}=670 \mathrm{~nm}\right)$ spectra of chloroform solutions of $\mathrm{P}(\mathrm{DTS}-\mathrm{BT})$, grafted $\mathrm{ZnO} @ \mathrm{P}(\mathrm{DTS}-\mathrm{BT})$ particles, and a mixture composed of bare $\mathrm{ZnO}$ and $\mathrm{P}(\mathrm{DTS}-\mathrm{BT})$.

\section{Scheme and figures}

Scheme 1.

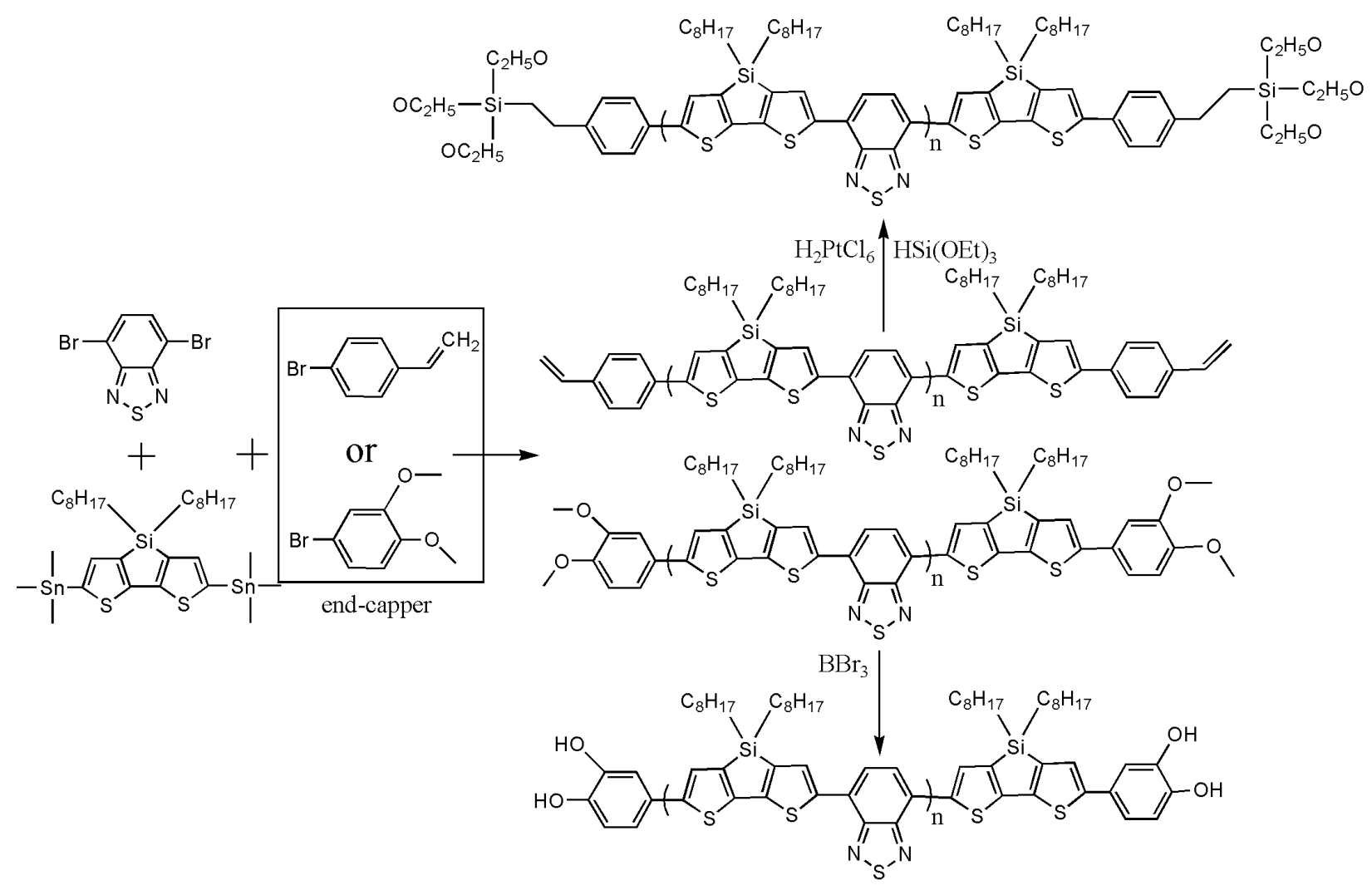


Figure 1.

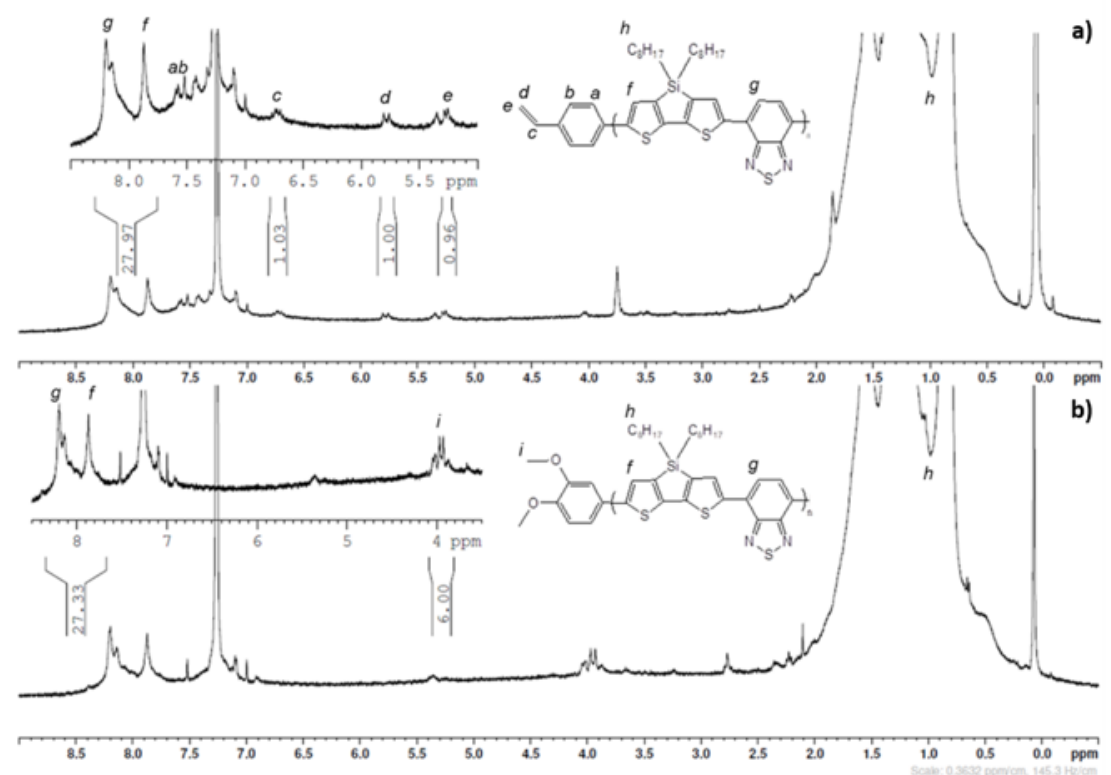

Figure 2.

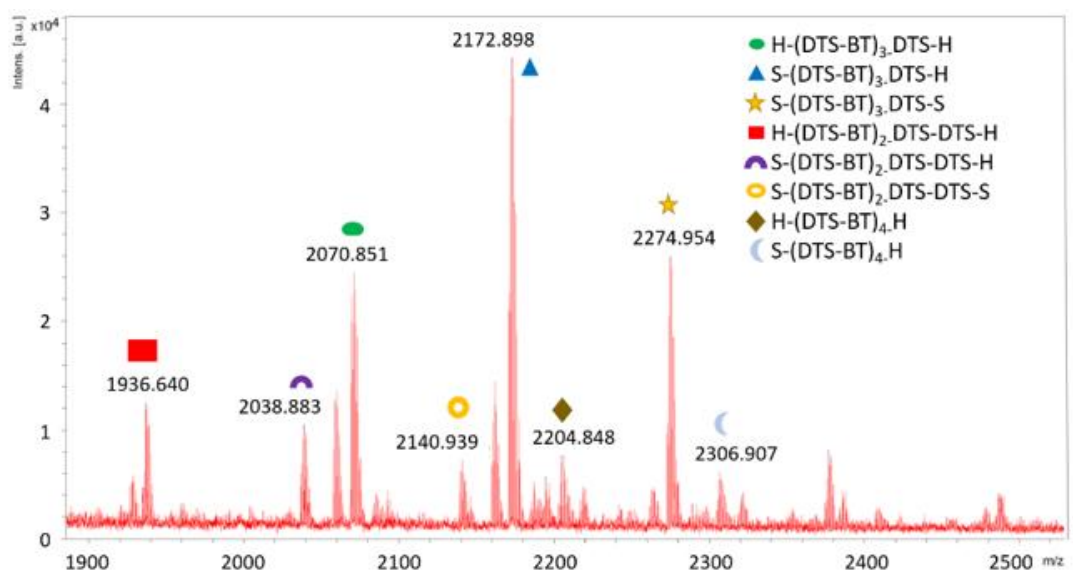


Figure 3

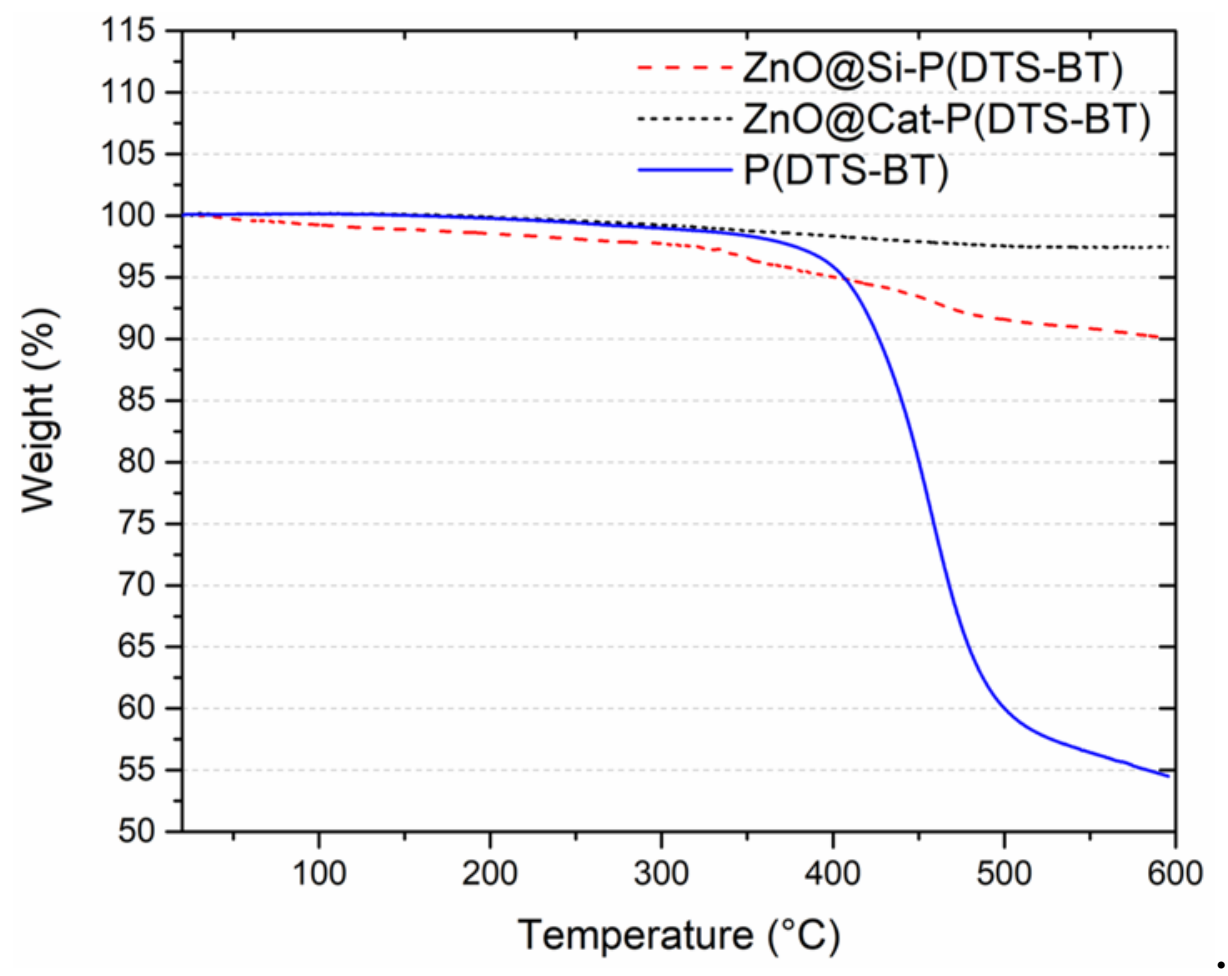

Figure 4. 


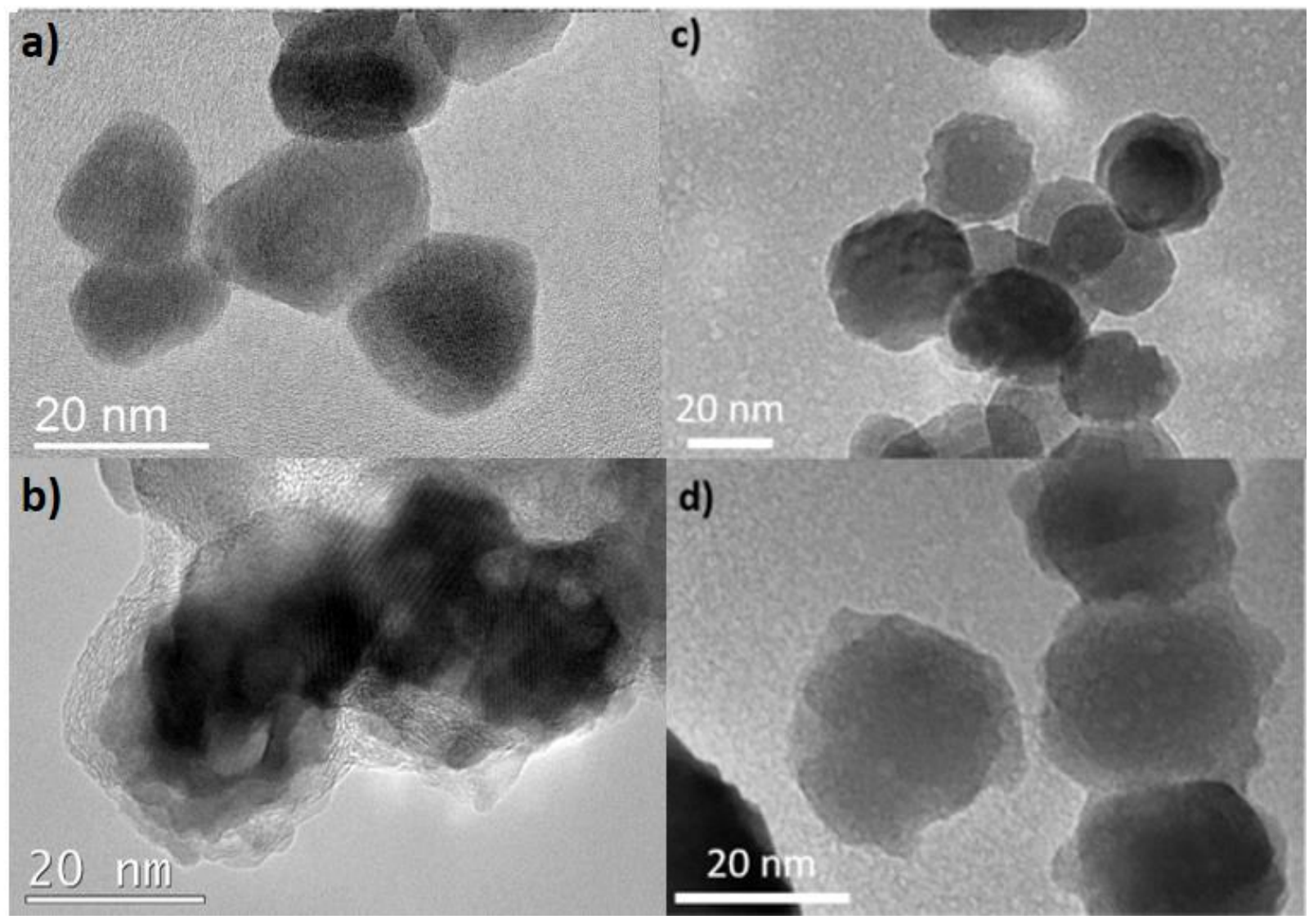


Figure 5.

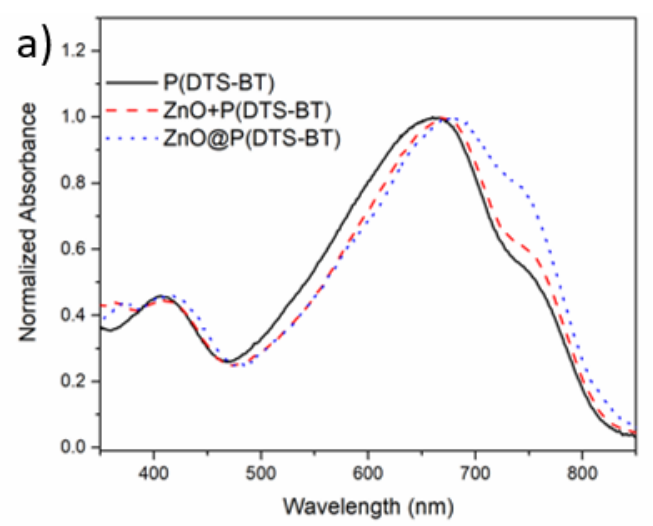

b)

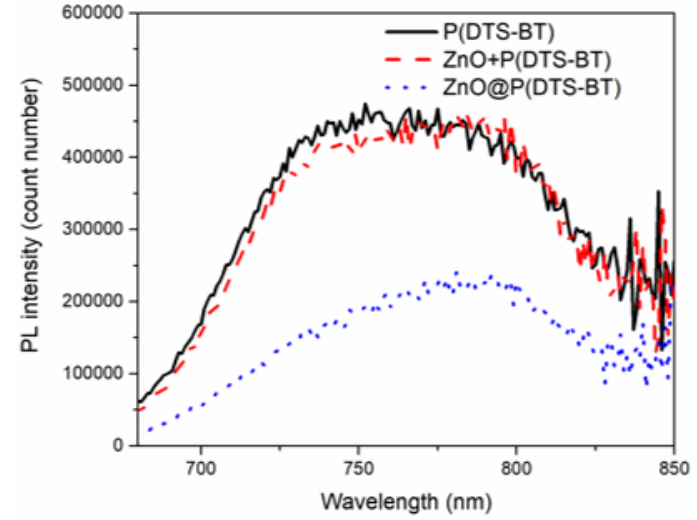




\section{Tables}

Table 1. Macromolecular characteristics of the synthesized polymers.

\begin{tabular}{cccccccccccc}
\hline Polymer & $r^{a}$ & $N_{D T S}{ }^{b}$ & $N_{B T}{ }^{b}$ & $N_{E G}{ }^{b}$ & $\begin{array}{c}n_{D T S B T} / \\
n_{E G}{ }^{c}\end{array}$ & $\begin{array}{c}n_{D T S B T} \\
/ n_{E G}{ }^{d}\end{array}$ & $M n t h^{c}$ & $M n^{d}$ & $M n^{e}$ & $M w^{e}$ & $\Xi^{e}$ \\
\hline P(DTS-BT) & 1 & 1 & 1 & 0 & $\infty$ & - & $\infty$ & - & 5000 & 9200 & 1.8 \\
P(DTS-BT)-BrS & 0.96 & 1 & 0.96 & 0.08 & 12 & 7 & 13300 & 7900 & 4800 & 8800 & 1.8 \\
P(DTS-BT)-BrS & 0.93 & 1 & 0.92 & 0.16 & 7 & 5 & 7200 & 5700 & 4500 & 8800 & 2.0 \\
P(DTS-BT)-BrV & 0.94 & 1 & 0.94 & 0.12 & 9 & 7 & 9200 & 8000 & 4000 & 8000 & 2.0 \\
\hline
\end{tabular}

${ }^{\mathrm{a}}$ feed ratio calculated according to equation $3,{ }^{\mathrm{b}}$ molar equivalent; ${ }^{\mathrm{c}}$ calculated from the Carothers equation (2) and based on the hypothesis of $100 \%$ conversion, i.e. 2 end-groups per chains; ${ }^{\mathrm{d}}$ based on ${ }^{1} \mathrm{H}$ NMR; ${ }^{\text {e }}$ measured by SEC with a UV detector at $678 \mathrm{~nm}$. 